\title{
INSECTICIDE SPRAYING IN SOYBEAN PLANTS: DIFFERENT NOZZLES MODELS AND AGROMETEOROLOGICAL CONDITIONS
}

\author{
Lilian L. Costa ${ }^{1^{*}}$, Nathan C. R. De Moura Aquino ${ }^{2}$ Ângela L. C. G. Carneiro ${ }^{3}$, \\ Dieimisson P. Almeida ${ }^{4}$, Marcelo Da C. Ferreira ${ }^{4}$
}

${ }^{1 *}$ Corresponding author. Instituto Federal Goiano, Campus Morrinhos/ Morrinhos - GO, Brasil. E-mail: lilian.costa@ifgoiano.edu.br

\begin{abstract}
KEYWORDS
spray volume deposit, application time, phytosanitary product, application technology.
\end{abstract}

\begin{abstract}
The aim of the experiment was to evaluate the quality of the spraying by the spray volume deposit provided by different nozzles models in two agrometeorological conditions of application. Four parameters related to spray quality were evaluated: spray volume deposit, droplet size, surface tension and contact angle. The treatments consisted of three nozzle models (AXI Twin 12002, TTJ 110015 and JAI 120015) and two application times (between 02:00 p.m. and 04:00 p.m. and between 08:00 a.m. and 09:30 a.m.). The spray volume deposit in the upper portion of the soybean plants was similar, but the JAI 120015 nozzle model produces more uniform droplet spectra and is safer than the AXI Twin 12002 and TTJ 110015 due to the highest drift risk. It is necessary to study alternatives that increase spray deposits in the lower portion of the crop, since in this study the distribution uniformity of the mixture in the portions of the soybean plant was low and the agrometeorological conditions interferes in the deposits of the sprayed mixture but is dependent on the selected nozzle model.
\end{abstract}

\section{INTRODUCTION}

The suitability of the application technology is an important tool in the management of the target organisms in the soybean crop. However, the application of crop protection products by spraying is a dynamic process with numerous opportunities for losses of the active ingredient.

One of the challenges is related to increasing penetration and deposition of spray droplets in the lower portion of the plants, a region in which pests and diseases have a higher preference for feeding and initiation of the infectious process, respectively. Another challenge is to adjust the application technology to the diverse agrometeorological conditions of producing areas of the country to reduce losses by drift and evaporation.

According to Cunha et al. (2011), the correct choice of the spray nozzle model that provides ideal diameters droplets according to the target and the agrometeorological conditions at the time of application may contribute to increase penetration and deposition of plant protection products.

Studying the droplets penetration in the canopy of peanut plants, Zhu et al. (2004) evaluated the performance of four types of spray nozzles (hollow cone, double flat fan, conventional flat fan and air induction), obtaining high deposit inside the plants with air induction nozzles. On the other hand, in a study by Guler et al. (2007), the authors reported that the spraying characteristics and the reduction potential of the air induction nozzle drift were like conventional nozzles with equivalent orifice sizes operated at close pressures.

According to $\mathrm{Yu}$ et al. (2009), the droplet diameter is recognized as one of the most important parameters that influence the control of the target organism. The use of fine droplets is generally recommended when greater coverage and penetration into the plants canopy profile are required. Although the fine droplet size is related to the control efficiency, there are other factors that must be considered, such as application time.

The application schedule also has a great influence on the quality of the spraying, especially when using fine droplets or in adverse agrometeorological conditions for the application. Researchers stated that fine droplets, especially those with diameters smaller than $100 \mu \mathrm{m}$, are more conducive to drift and evaporation losses, reducing the efficiency of application deposits and increasing the risks of

\footnotetext{
${ }^{2}$ Laboratório de Biocontrole Farroupilha LTDA/ Lucas do Rio Verde - MT, Brasil.

${ }^{3}$ Universidade Estadual de Goiás, Campus Ipameri/ Ipameri - GO, Brasil.

${ }^{4}$ Universidade Estadual Paulista "Júlio de Mesquita Filho", Campus Jaboticabal/ Jaboticabal - SP, Brasil.

Received in: 8-21-2017

Accepted in: 8-8-2018
}

Engenharia Agrícola, Jaboticabal, v.38, n.5, p.673-679, sep./oct. 2018 
environmental contamination, especially under adverse conditions of temperature and relative air humidity (Nuyttens et al., 2006; Matthews, 2008).

In view of the above, we aimed to evaluate the spraying quality through the spray volume deposit provided by different nozzle models, under two agrometeorological application conditions.

\section{MATERIAL AND METHODS}

The experiment was installed during the 2015/16 harvest in an experimental area of the State University of Goiás, University Unit of Ipameri, located at $17^{\circ} 43^{\prime} \mathrm{S}, 48^{\circ}$ $08^{\prime}$ W with altitude of 795 meters and average rainfall during the harvest was 243.10 millimeters, with the planting of the soybean crop, Embrapa "BRS Valiosa RR" cultivar.

The sowing was carried out in the no-tillage system, using $0.5 \mathrm{~m}$ spacing between rows, density of 18 seeds per meter of furrow and final stand of 220.000 soybean plants per hectare. Each experimental unit consisted of eight lines of six meters in length.

The crop treatments and applications of phytosanitary products were carried out in accordance with the recommendations indicated for the soybean crop. The velocity of displacement, flow and pressure of the nozzles used were adjusted to obtain the volume of $140 \mathrm{~L} \mathrm{ha}^{-1}$.

In the applications of the products of the active ingredient Acetamiprid and Alpha-cypermethrin (Fastac Duo $^{\circledR}, 100$ and $200 \mathrm{~g}$ a.i. $\mathrm{L}^{-1}, \mathrm{SC}$, Basf), at $0.3 \mathrm{~L} \mathrm{c.p.} \mathrm{ha}^{-1}+$ mineral oil (Assist ${ }^{\circledR}, 756$ g a.i. $\mathrm{L}^{-1}, \mathrm{CE}, \mathrm{Basf}$ ) at $0.5 \% \mathrm{v} \mathrm{v}^{-1}$, a $\mathrm{CO}_{2}$ pressurized sprayer was used with spray bar with four nozzles spaced $0.50 \mathrm{~m}$, equipped with the spray nozzles models; double flat jet (AXI Twin 12002, Jacto), flat deflection jet (TTJ 110015, Jacto), air induction flat jet (JAI 120015, Jacto).

Four evaluations related to spraying quality were carried out: spray volume deposition, droplet spectrum, surface tension and contact angle.

In the evaluations of the pulverized spray volume deposition, the experimental design used was randomized block design in a factorial scheme $(3 \times 2)$ and four replicates with two samples per replicate and in each portion of the plant. The treatments consisted of three nozzle models (AXI Twin 12002, TTJ 110015 and JAI 120015) and two application times, from 8:00 a.m. to 9:30 a.m. and from 2:00 p.m. to 4:00 p.m., used to obtain agrometeorological conditions characteristics as described in Table 1.

TABLE 1. Agrometeorological conditions at each time of application of the spray solution containing the insecticide with the three models of spray nozzles, AXI Twin 12002, TTJ 110015 and JAI 120015. Ipameri, GO, 2016.

\begin{tabular}{llccc}
\hline & Application time & T $\left({ }^{\circ} \mathrm{C}\right)$ & RH $(\%)$ & W.S $\left(\mathrm{km} \mathrm{h}^{-1}\right)$ \\
\hline Agrometeorological condition 1 & $08: 00$ a.m. to 09:30 a.m. & 30 & 60 & 0 to 2 \\
Agrometeorological condition 2 & $02: 00$ a.m. to 04:00 p.m. & 32 & 45 & 2 to 5 \\
\hline
\end{tabular}

$\mathrm{T}=$ average temperature; $\mathrm{RH}=$ Average relative humidity and, $\mathrm{W} . \mathrm{S}=$ Wind speed.

The sprayed droplets spectra were evaluated in a completely randomized design with three treatments and twelve replicates. The three nozzle models represented the treatments, with the spray solution and pressure $\left(45 \mathrm{lbf} \mathrm{in}^{-2}\right)$ used in field applications (Acetamiprid and Alphacypermethrin associated with mineral oil).

In the evaluation of the surface tension and contact angle, a completely randomized design was used, with three treatments and eight replications, respectively. Each experimental unit (repetition) consisted of one droplet. The spray solution (Acetamiprid and Alpha-cypermethrin associated with the mineral oil) used in the field constituted the treatments and two control spray solutions, one being the ultrapure water, without presence of ions, obtained through the Purelab equipment and the other through a public water supply.

To quantify the deposition of the pulverized spray solution, a metal marker formulated with copper sulfate $\left(25 \%\right.$ of $\left.\mathrm{Cu}^{2+}\right)$ was added to the spray solution at the concentration of $10 \mathrm{~g} \mathrm{~L}^{-1}$. After the applications of the spray solution with the marker, two soybean leaflets were collected in two plants per plot in the upper portion and another in the lower portion of the plant.

According to the method described by Oliveira \& Machado-Neto (2003) and ratified by Costa et al. (2015a) the collected soybean leaflets were placed in polyethylene bags, to which $100 \mathrm{~mL}$ of hydrochloric acid solution $(\mathrm{HCl})$ at $0.2 \mathrm{~mol} \mathrm{~L}^{-1}$ was added, followed by a 60 -minute rest period for the extraction of the metallic marker $\left(\mathrm{Cu}^{2+}\right)$ deposited in the leaflets by spraying of the different treatments. Subsequently, the marker $\left(\mathrm{Cu}^{2+}\right)$ extracted by the acid solution (recovered from the leaves) was quantified in an atomic absorption spectrophotometer.

The same leaflets used for the recovery of the metallic ion $\left(\mathrm{Cu}^{2+}\right)$ were washed and the leaf area was read through the LI-COR leaf area meter (Model LI 3100C).

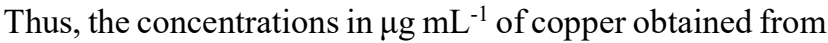
the spectrophotometer readings were related to the foliar areas measured, and later transformed into volume per unit area $\left(\mu \mathrm{L} \mathrm{cm}^{-2}\right)$ by the mathematical expression:

$$
\text { Ci.Vi=Cf.Vf. }
$$

That:

$$
\begin{aligned}
& C i=\text { initial concentration in the spray solution }\left(\mathrm{mg} . \mathrm{L}^{-}\right. \\
& \left.{ }^{1}\right) ; \\
& V i=\text { volume retained by the target }(\mathrm{mL}) \\
& C f=\text { concentration detected in optical density }(\mathrm{mg.L}- \\
& \left.{ }^{1}\right) \text { and, } \\
& \mathrm{Vf}=\text { dilution volume of the of each plant }(\mathrm{mL}) .
\end{aligned}
$$

The product of this mathematical expression was multiplied by 1.000 for transformation of the volume retained by the target from $\mathrm{mL}$ to $\mu \mathrm{L}$ per soybean leaflet, and divided by the leaf area of the respective leaflet.

The evaluated parameters of the droplet spectra produced by each nozzle model were the volumetric median diameter (VMD), the coefficient of uniformity of the sprayed droplets (Span) and the percentage of volume with droplets smaller than $100 \mu \mathrm{m}(\mathrm{V}<100 \mu \mathrm{m})$. 
The droplet diameter was determined by laser diffraction during the passage of the sprayed droplets by the sampling region of a particle size analyzer (Mastersizer, Malvern Instruments Limited), adjusted to evaluate droplets of 0.5 to $900 \mu \mathrm{m}$. The coefficient of uniformity was obtained by the [eq. (1)]:

$$
\text { Span }=\frac{D v 0.9-D v 0.1}{D v .5}
$$

That:

Span $=$ Coefficient of uniformity (dimensionless);

Dv0.1 and Dv0.9 refer to the droplet diameter $(\mu \mathrm{m})$, where $10 \%$ and $90 \%$, respectively, of the sprinkled volume are composed by droplets of smaller diameter than it, and

Dv 0.5 refers to the volumetric median diameter.

The decoding of the data, according to the algorithm elaborated for the characterization of the diameter of the droplets by laser diffraction were processed and tabulated directly by the program Mastersizer $\mathrm{S}^{\circledR}, 2.19$ version.

The three nozzle models were installed on a radial conveyor positioned at $0.4 \mathrm{~m}$ from the laser beam. Three samples of each nozzle model used in this study were analyzed and, for each of them, four repetitions of the sprinkler jets were performed, totaling twelve (12) repetitions per treatment.

For the surface tension and contact angle evaluations, the droplets formed by the spray solution sprayed at the field and controls were formed with the aid of a $500 \mu \mathrm{L}$ graduated microsyringe, and volumes of approximately $5 \mu \mathrm{L}$ being dispensed for each repetition.

The measurements of the surface tension and contact angle of each treatment were performed every second for one minute, through an automatic tensiometer equipped with a digital camera of high speed and definition, and the SCA20 software used for the equipment automation and evaluation of the obtained images using the pending droplet method to determine the kinetics of the surface tension and the sessile droplet method to determine the contact angle.

The data obtained (deposition, droplet spectrum parameters, surface tension and contact angle), after the confirmation of the normality assumptions of the residue (Shapiro-wilk) and homogeneity of variances (Cochran), were submitted to the $\mathrm{F}$ test of the variance analysis (ANOVA) and, when significant ( $p<0.01$ or $p<0.05$ ), the treatments averages were compared by the Tukey test.

For the statistical analysis of the surface tension and contact angle data, only the data obtained at the time one, thirty and sixty second, which characterize the beginning, the middle and the end of the evaluation of the kinetics of the surface tension and the contact angle of each treatment were considered.

\section{RESULTS AND DISCUSSION}

\section{Spray volume deposit}

The architecture of the soybean plant imposes barriers to the penetration of spray droplets in the plant canopy at the application time. Thus, it is expected that the spray volume deposit in the upper portion of the plants is higher than in the lower portion, as observed in this study, independent of the nozzle model and the agrometeorological condition at the application time (Table 2).

This result corroborates with several researchers that also reported an irregular distribution of the spray solution distribution in the soybean plants, with deposits in the lower portion significantly lower than those obtained in the upper portion (Prado et al., 2010; Cunha et al., 2011; Costa et al., 2015b).

According to Souza et al. (2007), in addition to the overlapping of existing leaves in the droplet path, there is also the possibility of losses by evaporation and/or drift of the smaller droplets, in adverse environmental conditions and by the greater distance covered, implying in fewer droplets in this part of the plant and, consequently, in irregularity in the volume deposited.

TABLE 2. Synthesis of the variance analysis and the average test for the spray volume deposit in different agrometeorological conditions (AC) of application, in the upper and lower portions of soybean plants, with different nozzle models. Ipameri, GO, 2015/16.

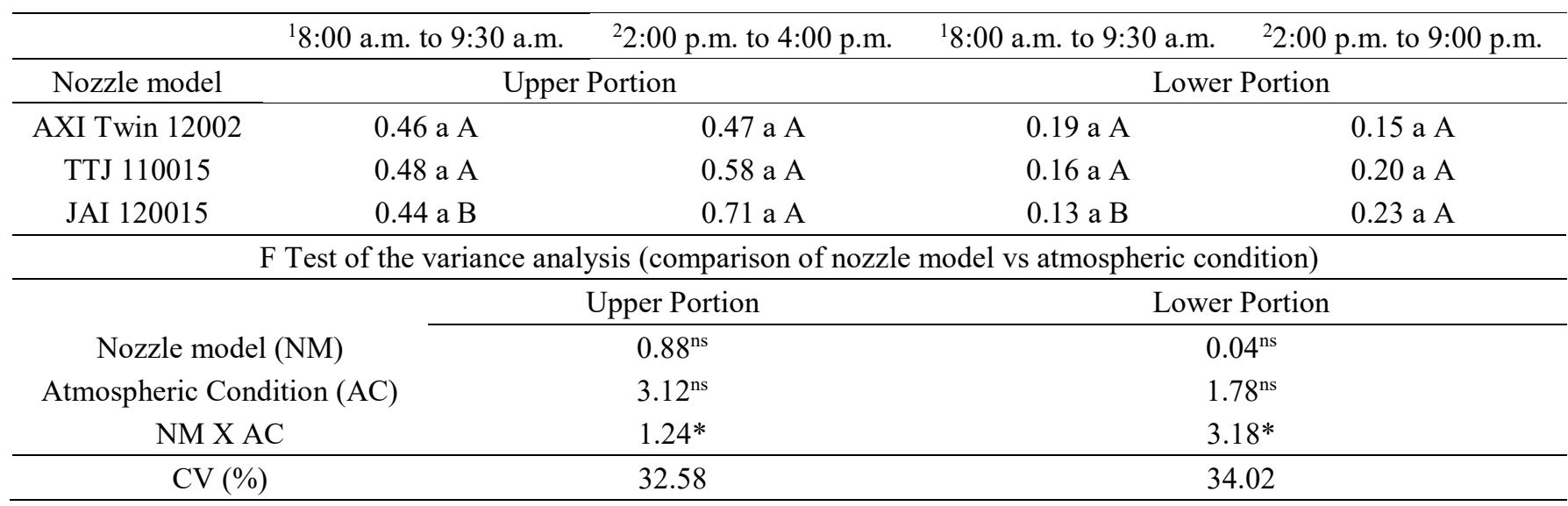

${ }^{1}$ Application from 8:00 a.m. to 9:30 p.m. = Agrometeorological condition 1 (temperature of $30^{\circ} \mathrm{C}, 60 \%$ relative humidity and wind speed from 0 to $2 \mathrm{~km} \mathrm{~h}^{-1}$ ). ${ }^{2}$ Application from 2:00 p.m. to 4:00 p.m. = Agrometeorological condition 2 (temperature of $32^{\circ} \mathrm{C}$, relative humidity of $45 \%$ and wind speed from 2 to $\left.5 \mathrm{~km} \mathrm{~h}^{-1}\right)$. Averages followed by the same lowercase letter in the column, and uppercase letters in the row do not differ statistically from each other by the Tukey test $(\mathrm{p}<0.05)$. By the F test: ${ }^{\text {ns }}$ significant test; * significant $(\mathrm{p}<0.05)$; CV (\%): coefficient of variation. 
Considering as one hundred percent (100\%), the spray volume deposit provided by the different nozzle models in the upper portion in relation to the deposit in the lower portion, none of the nozzle models, in the two agrometeorological conditions in which they were made, decreased the difference in deposit between the plant portions. That is, the droplets produced by all models tested had difficulty crossing the barrier imposed by the leaves mass of the upper third.

In potato plants, Vučajnk \& Bernik (2012), evaluating the deposit in the thirds of the plant provided by single-flat jet, double- flat jet, flat jet with air induction and conical jet spray nozzles, the authors verified that the nozzles with air induction provided lower reduction in the deposit value from the upper and lower portion compared to other nozzle types. In this study, this result was not observed.

When comparing, among the different nozzle models, the spray volume deposit provided in both upper and lower portions of the plants, in the two agrometeorological conditions, there were no significant differences between them (Table 2).

The AXI Twin 12002 nozzle model produces double-flat jet and fine droplet spectrum, TTJ 110015 produces single-flat jet and medium droplet spectrum and JAI 120015 produces flat jet with air induction and medium droplet spectrum (Table 3). Based on this information and in other studies, where it was concluded that there is a greater deposit of fine droplets in the lower portion of the plants when compared to medium or coarse drops, the AXI Twin nozzle model produce fine droplet spectrum and it was expected to provide greater spray volume deposit in the upper and/or lower part of the plant in relation to the other models studied.

As for the deposit obtained by each nozzle model in the two agrometeorological conditions, there were no significant differences for the AXI Twin 12002 and TTJ 110015 models, both in the upper and lower portions (Table
2). On the other hand, the JAI 120015 nozzle model provided a larger spray volume deposit, in the upper and lower portions in the agrometeorological condition 2, corresponding to the application period from 2:00 p.m. to 4:00 p.m. (Table 2).

As favorable conditions for an application, Nuyttens et al. (2006) state that higher relative humidity, lower temperature and wind speed reduce the risks of drift loss and evaporation regardless of the application technology used. Thus, it was expected that the deposit of the droplets generated by the different nozzle models would be higher in the agrometeorological condition 1 (Temperature $30^{\circ} \mathrm{C}$, Relative Humidity $60 \%$ and Wind Speed from 0 to $2 \mathrm{~km} . \mathrm{h}^{-}$ $\left.{ }^{1}\right)$ corresponding to the period from 08:00 a.m. to 09:30 a.m. (Table 2), than in the agrometeorological condition 2 (Temperature $32^{\circ} \mathrm{C}$, Relative Humidity $45 \%$ and Wind Speed 2 to $5 \mathrm{~km} \mathrm{~h}^{-1}$ ), corresponding to the period from 2:00 p.m. to 4:00 p.m.

It is possible that the absence of winds, practically during all the time of the applications carried out in the agrometeorological condition 1, contributed for this result. The absence of wind is detrimental due to the greater chance of occurring thermal inversion or of not having enough energy to deposit the droplets, especially when these are thin or very thin.

\section{Droplets Spectrum}

The values of the volumetric median diameter (VMD), obtained for the different nozzle models by the statistical analysis, differed from each other (Table 3). But, according to the American Society of Agricultural \& Biological Engineers (ASABE, 2009), there is a classification pattern of the droplets spectra produced by the nozzles in a spray. Thus, there is an extremely fine class $(<60 \mu \mathrm{m})$, very thin $(61-105 \mu \mathrm{m})$, thin $(106-235 \mu \mathrm{m})$, medium $(236-340 \mu \mathrm{m})$, thick $(341-403 \mu \mathrm{m})$, very thick $(404-502 \mu \mathrm{m})$, extremely thick $(503-665 \mu \mathrm{m})$ and ultrathick $(>665 \mu \mathrm{m})$.

TABLE 3. Synthesis of the variance analysis and the test of averages for the variables: volumetric median diameter (VMD) $(\mu \mathrm{m})$, the percentage of spray volume composed of droplets with a diameter less than or equal to 100 micrometers $(\% \leq 100 \mu \mathrm{m})$ and the Coefficient of Uniformity (Span) of the sprayed droplets by different spray nozzles. Jaboticabal, SP, 2016.

\begin{tabular}{cccr}
\hline Nozzle models & VMD $(\mu \mathrm{m})$ & $\%<100 \mu \mathrm{m}$ & Span \\
\hline AXI Twin 12002 & $186.68 \mathrm{c}$ & $13.49 \mathrm{~b}$ & $2.09 \mathrm{~b}$ \\
TTJ 110015 & $261.07 \mathrm{~b}$ & $15.41 \mathrm{~b}$ & $1.45 \mathrm{a}$ \\
JAI 120015 & $285.23 \mathrm{a}$ & $12.46 \mathrm{a}$ & $3.46 \mathrm{a}$ \\
\hline F & $2,216.52^{* *}$ & $33.84^{* *}$ & $391.75^{* *}$ \\
\hline SMD & 3.78 & 0.92 & 0.06 \\
\hline CV (\%) & 1.55 & 6.76 & 3.85 \\
\hline
\end{tabular}

Averages followed by same letter do not differ from each other by Tukey test $(\mathrm{P}<0,05)$; SMD: Significant minimum difference; $\mathrm{CV}(\%)$ : coefficient of variation, $* * \mathrm{~F}$ test significant $(\mathrm{p}<0.01)$. 
According to the classification standard of ASABE (2009), the spectra of the droplets produced by the studied models are classified as fine (AXI Twin 12002) and medium (TTJ 110015 and JAI 120015) (Table 3). This result was not expected for the JAI 120015 model because at the pressure of $45 \mathrm{lbf} \mathrm{in}^{-2}$, which was used in this experiment, this model should produce thick drops according to the manufacturer's indication. This difference may be related to the composition of the spray solution (Almeida et al., 2016; Costa et al., 2017a; Costa et al., 2017b). It is worth noting that the evaluations for the classification of the droplet spectrum produced by the different nozzle models available on the market are measured with standard spray solutions in accordance with ANSI/ASAE S572.1 standard from ASABE (2009).

Some authors cite that one of the factors that indicate the potential risk of nozzle drift is the percentage of droplet volume with a diameter of less than $100 \mu \mathrm{m}$ (Arvidsson et al., 2011; Oliveira et al., 2015; Almeida et al., 2016). Among the nozzle models tested, the JAI 110015 provided a lower percentage of droplets with a diameter of $100 \mu \mathrm{m}$ or less, suggesting that this model offers greater safety in the applications in relation to the others for the drift risk (Table 3).

This result is justified because the JAI 120015 nozzle model is considered a drift reducer because it has air induction, that is, it uses the Venturi principle, resulting in the formation of larger diameter droplets, which normally present a lower drift risk by significantly reducing the spray volume of droplets with a diameter of less than $100 \mu \mathrm{m}$ in relation to the other models studied.

The uniformity coefficient expressed is the uniformity of the spray droplets spectrum. In this study, the AXI twin 12002 nozzle model presented higher coefficient of uniformity than the other models tested, indicating the production of more heterogeneous droplets (Table 3 ). The higher the coefficient of uniformity is the greater will be the spray droplets size range, that is, the lower will be the uniformity of the droplet spectrum produced.

\section{Surface tension and contact angle}

The addition of the insecticide in the spray solution reduced the surface tension of the water by $50 \%$ at the end of the evaluation (Table 4). This reduction in surface tension is probably due to the performance of the Mineral Oil adjuvant $\left(\right.$ Assist $^{\circledR}, 756 \mathrm{~g}$ a.i. $\mathrm{L}^{-1}, \mathrm{CE}$, Basf), which was added to the spray solution.

Reduction in the water surface tension by adjuvants has already been demonstrated in several studies that evaluate the effects of adjuvants on the physicochemical properties of spray solutions (Iost \& Raetano, 2010, Decaro Junior et al., 2015). However, in the insecticide formulation used, there are compounds that alter the physico-chemical properties of the spray solution.

TABLE 4. Synthesis of the variance analysis and the test of averages for surface tension of the treatments at $1 \mathrm{~s}, 30 \mathrm{~s}$ and $60 \mathrm{~s}$ after the formation of the droplets and the beginning of the measurements. Jaboticabal, SP, 2016.

\begin{tabular}{|c|c|c|c|}
\hline \multicolumn{4}{|c|}{ Superficial tension $\left(\mathrm{mNm}^{-1}\right)$} \\
\hline \multirow{2}{*}{ Treatments } & \multicolumn{3}{|c|}{ Time (seconds) } \\
\hline & $1 \mathrm{~s}$ & $30 \mathrm{~s}$ & $60 \mathrm{~s}$ \\
\hline${ }^{1}$ Acetamiprid and Alpha-cypermethrin + Mineral oil & $59.00 \mathrm{a}$ & $42.21 \mathrm{a}$ & $38.73 \mathrm{a}$ \\
\hline Ultrapure water & $80.20 \mathrm{~b}$ & $80.74 \mathrm{~b}$ & $79.42 \mathrm{~b}$ \\
\hline Public water supply & $81.03 \mathrm{~b}$ & $84.86 \mathrm{~b}$ & $85.17 \mathrm{~b}$ \\
\hline $\mathrm{F}$ & $26.20 * *$ & $140.67 * *$ & $108.99 * *$ \\
\hline SMD & 8.70 & 7.07 & 8.36 \\
\hline $\mathrm{CV}(\%)$ & 9.40 & 8.10 & 9.99 \\
\hline
\end{tabular}

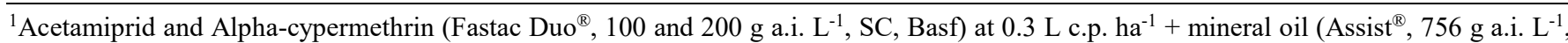
$\mathrm{EC}, \mathrm{Basf})$ at $0.5 \% \mathrm{v} \mathrm{v}^{-1}$. Averages followed by the same letter did not differ by Tukey test $(\mathrm{p}<0.05)$; SMD: significant minimum difference; $\mathrm{CV}(\%)$ : coefficient of variation, ${ }^{* *} \mathrm{~F}$ test significant $(\mathrm{p}<0.01)$.

The surface tension is an important property of the spray solution because the greater retention or adhesiveness of the phytosanitary products on the leaf surface is a consequence of the greater wettability, which occurs due to the greater area of contact obtained by the reduction of the surface tension (Xu et al., 2011).Therefore, the surface tension of the droplets and their interaction with the target surface influence not only the wettability but also the absorption process of the phytosanitary products, which is fundamental for the application efficiency.
According to Iost \& Raetano (2010), there is a strong relation between the surface tension and the contact angle of the droplets. Any compound, by decreasing the surface tension of the water, increases the contact surface of the droplet and produces greater scattering, reducing the contact angle of the liquid with the surface. This fact was verified in this experiment, in which in the spray solution with the insecticide, a lower value of contact angle was observed in relation to ultrapure water or public water supply (Table 5). 
TABLE 5. Synthesis of the variance analysis and the test of averages for contact angle $\left(\theta^{\circ}\right)$ of the droplets on artificial surface (glass) at 1s, 30s and 60s after the formation and deposit of the droplets and the beginning of the measurements. Jaboticabal, SP, 2016.

\begin{tabular}{cccc}
\hline & Contact angle $\left(\theta^{\circ}\right)$ & \multicolumn{3}{c}{ Time (seconds) } \\
\cline { 2 - 4 } Treatments & \multicolumn{1}{c}{$1 \mathrm{~s}$} & \multicolumn{1}{c}{$30 \mathrm{~s}$} & \multicolumn{1}{c}{$60 \mathrm{~s}$} \\
\hline Acetamiprid and Alpha-cypermethrin + Mineral oil & $91.82 \mathrm{~b}$ & $78.77 \mathrm{a}$ & $73.90 \mathrm{a}$ \\
Ultrapure water & $109.56 \mathrm{a}$ & $108.78 \mathrm{~b}$ & $104.81 \mathrm{~b}$ \\
Public water supply & $111.83 \mathrm{a}$ & $110.82 \mathrm{~b}$ & $109.98 \mathrm{~b}$ \\
\hline F & $191.12^{* *}$ & $489.11^{* *}$ & $371.71^{* *}$ \\
SMD & 2.82 & 2.85 & 3.65 \\
CV (\%) & 2.15 & 2.28 & 3.00 \\
\hline
\end{tabular}

Averages followed by same letter do not differ from each other by Tukey test $(\mathrm{P}<0,05)$; SMD: Significant minimum difference; $\mathrm{CV}(\%)$ : coefficient of variation, $* * \mathrm{~F}$ test significant $(\mathrm{p}<0.01)$.

\section{CONCLUSIONS}

The studied nozzle models provide similar spray volume deposits in the upper and lower thirds of the soybean plant, so the JAI 120015 produces more uniform droplet spectra and lower drift risk than the AXI Twin 12002 and TTJ 110015 models.

There is a need to study other alternatives that increase spray deposits, especially in the lower part of the plant.

The distribution of the spray solution in the soybean plants, provided by the nozzle models studied is not uniform.

The agrometeorological condition interferes in the deposition of the sprayed solution, but it is dependent on the selected nozzle model.

Among the evaluated nozzle models, the JAI 120015 is the most suitable for spraying the insecticides in the soybean crop.

\section{ACKNOWLEDGMENTS}

We would like to thank to IF Goiano, Morrinhos Campus, GO; the State University of Goiás, Ipameri Campus, GO and UNESP, the São Paulo State University, Jaboticabal Campus, SP, by the support in carrying out the experiment.

\section{REFERENCES}

Almeida DP, Agostini AR, Yamauchi AK, Decaro Júnior ST, Ferreira MC (2016) Application volumes and sizes of droplets for the application of diquat herbicide in the control of Eichhornia crassipes. Planta Daninha 34(1):171-179.

Arvidsson T, Bergström L, Kreuger J (2011) Spray drift as influenced by meteorological and technical factors. Pesticide Management Science 67(5):586-598. DOI: http://dx.doi.org/10.1002/ps.2114. Epub 2011 Feb 28

ASABE - American Societyof Agricultural and Biologial Engineers (2009) Spray nozzle classification by droplet spectra. Available in: https://pubs.ext.vt.edu/442/442031/442-031_pdf.pdf. Accessed: Jun 17, 2017.
Costa LL, Ferreira MC, Campos HBN, Lasmar O, Cruz MCP (2015a) Recovery of metallic markers sprayed on soybean plants. Australian Journal of Crop Science 9(9):807-811.

Costa LL, Ferreira MC, Campos HBN, Carvalho GGF, Barbosa JC (2015b) The mixture sprayed by hydraulic and centrifugal energy nozzles for the control of Asian soybean rust. Acta Scientiarum: agronomy 37(4):425-433. DOI: http://dx.doi.org/10.4025/actasciagron.v37i4.19598

Costa LL, Silva HJPS, Almeida DP, Ferreira MC; Pontes NC (2017a) Droplet spectra and surface tension of spray solutions by biological insecticide and adjuvants. Engenharia Agrícola 37(2): 292-301.

Costa LL, Carneiro ALCG, Souza ADV, Almeida DP, Ferreira MC (2017b) Caracterização da aplicação com diferentes inseticidas e pontas de pulverização na cultura da soja. Revista Engenharia na Agricultura 25(2):116-123.

Cunha JPAR, Farnese AC, Olivet JJ, Villalba J (2011) Deposição de calda pulverizada na cultura da soja promovida pela aplicação aérea e terrestre. Engenharia Agrícola 31(2):343-351. DOI:

http://dx.doi.org/10.1590/S0100-69162011000200014

Decaro Junior ST, Ferreira MC, Lasmar O (2015) Physical characteristics of oily spraying liquids and droplets formed on coffee leaves and glass surfaces. Engenharia agrícola 35(3):588-600. DOI: http://dx.doi.org/10.1590/1809-4430Eng.Agríc.v35n3p588-600/2015

Guler H, Zhu HE, Kerksen RC, Yu Y, Krause CR (2007) Spray characteristics and drift reduction potential with air induction and conventional flat-flan nozzles. Transaction of the ASABE 50(3):745-754. DOI:

http://dx.doi.org/10.13031/2013.23129

Iost CAR, Raetano CG (2010) Tensão superficial dinâmica e ângulo de contato de soluções aquosas com surfatantes em superfícies artificiais e naturais. Engenharia Agrícola 30(4):670-680. DOI: http://dx.doi.org/10.1590/S010069162010000400011 
Matthews GA (2008) Developments in application technology. Environmentalist 28(1):19-24.

Nuyttens D, DeSchampheleire M, Steurbaut W, Baetens K, Verboven P, Nicolaï B, Ramon H, Sonck B (2006) Experimental study of factors influencing the risk of drift from field sprayers, part 1: meteorological conditions. Aspects of Applied Biology 77(2):321-329. Available in: http://hdl.handle.net/1854/LU-703958

Oliveira RB, Antuniassi UR, Gandolfo MA (2015) Spray adjuvant characteristics affecting agricultural spraying drift. Engenharia Agrícola 35(1): 109-116. DOI: http://dx.doi.org/10.1590/1809-4430-

Eng.Agríc.v35n1p109-116/2015

Oliveira ML, Machado-Neto JG (2003) Use of tracer in the determination of respiratory exposure and relative importance of exposure routes in safety of pesticide applicators in citrus orchards. Bulletin of Environmental Contamination and Toxicology 70(3):415-21. DOI: 10.1007/s00128-003-0002-8

Prado EP, Raetano CG, Aguiar Junior HO, Pogetto MHFA, Christovam RS, Gimenes MJ, Araújo D (2010) Velocidade do ar em barra de pulverização na deposição da calda fungicida, severidade da ferrugem asiática e produtividade da soja. Summa Phytopathologica 36(1):4550. DOI: http://dx.doi.org/10.1590/S010054052010000100008
Souza RT, Velini ED, Palladini LA (2007) Aspectos metodológicos para análise de depósitos de pulverizações pela determinação dos depósitos pontuais. Planta Daninha 25(1):195-202. DOI: http://dx.doi.org/10.1590/S010083582007000100022

Vučajnk F, Bernik R (2012) Improved quality of fungicide deposition and coverage of potato leaves using flat fan airinjector nozzle IDK. Acta agriculturae Slovenica 99(2):151-164. DOI: http://dx.doi.org/10.2478/v10014$012-0015-2$

Xu L, Zhu H, Ozkan E, Bagley B, Krause CR (2011) Droplet evaporation and spread on waxy and hairy leaves associated with the type and concentration of adjuvants. Pest Management Science 67(7):842-851. DOI: http://dx.doi.org/10.1002/ps.2122

Yu Y, Zhu H, Frantz J, Reding ME, Chan KC (2009) Evaporation and coverage area of pesticide droplets on hairy and waxy leaves. Biosystems Engineering 101(3): 111.DOI: 10.1016/j.biosystemseng.2009.08.006

Zhu H, Dorner JW, Rowland DL, Derksen RC, Ozkan HE (2004) Spray penetration into peanut canopies with hydraulic nozzle tips. Biosystems Engineering 87(3): 275283. DOI:

https://doi.org/10.1016/j.biosystemseng.2003.11.012 